
\title{
28 Research Suare \\ Detection of High Risk People for Diabetes by American Diabetes Association Risk Score in PERSIAN Guilan Cohort Study
}

\section{Tolou Hasandokht}

Guilan University of Medical Sciences

Farahnaz Joukar

Guilan University of Medical Sciences

Saman Marroufizadeh

Guilan University of Medical Sciences

Sahar Sibevey

Guilan University of Medical Sciences

Mohammadreza Naghipour

Guilan University of Medical Sciences

Fariborz Mansour-Ghanaei ( $\nabla$ fmansourghanaei@gmail.com )

Guilan University of Medical Sciences

Research

Keywords: ADA, Diabetes Mellitus, Risk score, Guilan cohort study

Posted Date: November 20th, 2020

DOl: https://doi.org/10.21203/rs.3.rs-111051/v1

License: (9) (i) This work is licensed under a Creative Commons Attribution 4.0 International License. Read Full License 


\section{Abstract}

Background: To determine prevalence of high risk individuals for diabetes mellitus (DM) and pre DM based on American Diabetes Association (ADA) risk score among Iranian people.

Methods: Present study was based on 7989 non diabetic subjects aged 35-70 years from 10520 PERSIAN Guilan Cohort Study (PGCS) participants. ADA risk score was calculated for every individual through online calculator. Receiver operating characteristic (ROC) curves was used to study diagnostic accuracy of the anthropometric indices for detecting individuals with high risk ADA score for developing DM, represented by area under the curve (AUC).

Results: From 7989 study subjects, ADA risk score found 3874 (48.5\%) and 19122 (23\%) at risk for developing PreDM and DM, respectively. The results of ROC curve analyses showed the highest diagnostic value was related to waist circumference (WC) followed by Body Mass Index (BMI) (0.695 and 0.693, respectively). The cut-points of WC and BMI for identifying high risk people for DM were 97 and 29, respectively.

Conclusions: A large number of our participants had high ADA risk score for developing DM and PreDM that provide the importance of prevention strategies. WC seems to be highest diagnostic value in identifying people (men and women) with DM.

\section{Introduction}

Diabetes mellitus (DM) is one of the most prevalent chronic diseases in the word with high cost of medical services due to complications of the disease [1]. Over the past decade, the prevalence of diabetes has risen due to aging, urbanization and increased unhealthy behaviors like bad dietary habits, physical inactivity[2].According to International Federation of Diabetes (IDF) Atlas for Diabetes, middle east region and Iran was known as one the of counties with the high prevalence of diabetes. It is estimated 9.2 million Iranian individuals will have diabetes by the year 2030[3]. Hence, this dramatic increase in the diabetes prevalence results the high economic cost for management of disease and its complications [4]. In spite of genetic susceptibility, environmental factors like unhealthy diet habit and sedentary lifestyle play an important role in the development of diabetes [5]. Evidence from studies has clearly shown early identification and behavioral intervention to loose weight, increase physical activity and choose healthy diet can significantly decrease the incidence of diabetes and prediabetes [6, 7]. To decrease the burden of DM, several guidelines and World Health Organization (WHO) recommended strategies for early detection of individuals are at risk of diabetes [8-10]. Till now, several non invasive and easily practical risk prediction model have been developed to identifying those with high risk for the diabetes including FINDRISC (Finnish Diabetes Risk Score)[11], AUSDRISK (Australian Type 2 Diabetes Risk Assessment Tool)[12], ADA (American Diabetes Association)RISK SCORE [13, 14], and a risk score had been developed in Thailand [15]. In a recent study [16] the validity of the ADA risk prediction models had been confirmed for identifying high risk individuals for type 2 diabetes in a large sample of Iranian population related to 
the Tehran Lipid and Glucose Study (TLGS). In the recent report, over the $70 \%$ of Guilan population were found to be overweight or obese [17] and consequently at risk of non communicable disease. Hence, identifying high risk people and implementing prevention community based program seems to be substantial. The aim of present study was to assess the prevalence of high risk individuals for diabetes or prediabetes among Iranian individuals according to ADA risk score.

\section{Materials And Methods}

\section{Study design and population}

This is a cross sectional study on PGCS participant (PERSIAN Guilan Cohort Study), a prospective, population-based cohort study in Guilan has been described in detail elsewhere[17-19].Briefly, The Guilan cohort study(GCS) was conducted on 10520 participants aged between 35-70 years in Guilan province, northern Iran, between October 8, 2014 and January 20, 2017 as part of the Prospective Epidemiological Research Studies in Iran (PERSIAN).Eligible subjects were contacted through phone by trained interviewers who can spoke the native language of the region and invited to participate the study. After signed informed constant all study data including demographic characteristics, socio-economic status, lifestyle and sleep habits, Anthropometric indices and blood pressure were recorded by a trained research assistants. Also biological samples were collected. In phase 2, annually active follow up was planed for next 15 years for all participants according to the PERSIAN cohort protocol [18]. Present study data included 7989 non diabetic participants of the GCS study. Diabetic subjects were excluded. Subjects with DM in the GCS were defined as 1) history of diagnosed DM 2) history of anti diabetic medication consumption 3) fasting blood sugar (FBS)>126 in the initial cohort laboratory data [17].

\section{Data collection and measurement}

For every participant, we retrieved data from GCS database that were collected through interviews, physical examinations, and laboratory tests according to cohort protocol [19]. For the present study, data included demographic factors like age, sex, living location (city or rural), Marital status, Occupation (employed, unemployed), anthropometric indices including weight, height, hip and waist circumference, waist to hip ratio (WHpR) and waist to height ratio (WHtR), history of hypertension (HTN), gestational DM in women subjects and any history of DM in their first degree family like father, mother, sister or brother and finally information about physical activity. All anthropometric indices including weight, height, Hip Circumference (HC), Waist Circumference (WC), WHpR, and WHtR were measured by trained research assistants according to GCS protocol. Body mass index (BMI) was categorized as underweight (BMl<18.5 $\mathrm{kg} / \mathrm{m} 2)$, normal weight (BMl= 18.5-24.99 kg/m2), overweight (BMl= 25-29.9 kg/m2) and obese (BMl $\geq 30$ $\mathrm{kg} / \mathrm{m} 2$ ). The level of Physical activity was reported as metabolic equivalent rates (METs) based on self reported daily activity PERSIAN cohort questionnaire. 
The risk of developing DM or prediabetes was calculated for every individual based on ADA risk prediction model through online calculator [13] the ADA risk prediction model was developed based on American population higher than 20 years without DM to identify high risk individuals for DM or prediabetes. ADA risk score included 7 questions like age, sex, race, weight, height, family history of DM, history of gestational DM, history of HTN and physical activity. Total score was calculated between 0-11. The higher score represent higher risk of diabetes. The cut point 5 or higher shows the high risk for DM and cut point 4 shows the high risk for prediabetes [20]. All required data for calculating ADA risk were extracted from cohort study. Family history of DM in ADA risk score was defined any history of diabetes in mother, father, sister or brother. Gestational diabetes in PERSIAN cohort was considered yes if women answered yes to the question "did you have a history of diabetes in pregnancy or did you have given birth a baby with $\geq 4 \mathrm{~kg}$ ?" For race, all participants were defined as white. For physical activity, the question in ADA risk score tool was "are you physically active? Yes or no" Low level of physical activity in PERSIAN cohort was defined as less than mean METs rates of participants (41 METs/hour/day) that have been previously descried in details [17].

\section{Ethics}

This research project was approved by the Ethics Committee of the Gastrointestinal and Liver Disease Research Center and Guilan University of Medical Sciences (code number IR.GUMS.REC.1398.241). All participants expressed their consent for participation in the research.

\section{Statistical analysis}

In this study, continuous variables were expressed as mean \pm standard deviation (SD) and categorical variables as frequency (percentage). One-way ANOVA and Chi-square test were used to compare demographic characteristics and anthropometric indices among normal, prediabetes, and diabetes groups. Receiver operating characteristic (ROC) curves were used to study diagnostic accuracy of the anthropometric indices for detecting patients with diabetes, represented by area under the curve (AUC). An AUC value of 0.5 indicates an entirely random classifier and an AUC value of 1 indicates perfect classifier. The best cut-off value was defined as the value with the highest accuracy that maximizes you den's $\mathrm{J}$ statistic, i.e. $\mathrm{J}=$ sensitivity + specificity -1 . Data analysis was performed using IBM SPSS Statistics for Windows, version 26.0 (IBM Corp., Armonk, NY, USA), and a $\mathrm{P}<0.05$ was considered statistically significant.

\section{Result}

\section{Characteristics of the participants}

Totally, of 10520 participants, 7989 non diabetic individuals were included in the study. Prevalence of DM in PERSIAN Guilan Cohort Study (PGCS) was 2531 (24.1\%) [20]. Demographic characteristics and 
anthropometric indices of the participants are presented in Table 1. The geographic distributions of study participants according to ADA score category (normal, high risk for preDM, high risk for DM) are presented in Fig. 1.The mean age of the participants was $50.52 \pm 8.75$ years. More than, $51 \%$ were female, $91.2 \%$ were married, $54.9 \%$ were resident in rural area, and $27.5 \%$ had normal BMI, $53.6 \%$ had a family history of diabetes. 
Table 1

Demographic and clinical characteristics of adult participants based on ADA risk scores in the PERSIAN Guilan Cohort Study $(\mathrm{n}=7989)$

\begin{tabular}{|c|c|c|c|c|c|c|}
\hline & Total(N) & Normal (N) & $\begin{array}{l}\text { Prediabetes } \\
\text { (P) }\end{array}$ & $\begin{array}{l}\text { Diabetes } \\
\text { (D) }\end{array}$ & $P$ & \\
\hline Age (y) & $\begin{array}{l}50.52 \pm \\
8.75\end{array}$ & $\begin{array}{l}44.62 \pm \\
5.83\end{array}$ & $48.59 \pm 7.48$ & $54.84 \pm 8.40$ & $<.001$ & $\begin{array}{l}\mathrm{N}<\mathrm{P}< \\
\mathrm{D}\end{array}$ \\
\hline \multicolumn{7}{|l|}{ Sex } \\
\hline Male & $\begin{array}{l}3898 \\
(48.8)\end{array}$ & $990(25.4)$ & $913(23.4)$ & 1995 (51.2) & $\begin{array}{l}< \\
0.001\end{array}$ & \\
\hline Female & $\begin{array}{l}4091 \\
(51.2)\end{array}$ & $\begin{array}{l}1213 \\
(29.7)\end{array}$ & $999(24.4)$ & $1879(45.9)$ & & \\
\hline Marital status & & & & & $<.001$ & \\
\hline Single & 259 (3.2) & $129(49.8)$ & $53(20.5)$ & $77(29.7)$ & & \\
\hline Married & $\begin{array}{l}7282 \\
(91.2)\end{array}$ & $\begin{array}{l}1969 \\
(27.0)\end{array}$ & $1772(24.3)$ & 3541 (48.6) & & \\
\hline Widowed & $348(4.4)$ & 65 (18.7) & $68(19.5)$ & $215(61.8)$ & & \\
\hline Divorced & $100(1.3)$ & $40(40.0)$ & $19(19.0)$ & $41(41.0)$ & & \\
\hline Occupation & & & & & $\begin{array}{l}<.001 \\
0.001\end{array}$ & \\
\hline Employed & $\begin{array}{l}3372 \\
(42.2)\end{array}$ & 793 (23.5) & 785 (23.3) & $1794(53.2)$ & & \\
\hline Unemployed & $\begin{array}{l}4617 \\
(57.8)\end{array}$ & $\begin{array}{l}1410 \\
(30.5)\end{array}$ & $1127(24.4)$ & $2080(45.1)$ & & \\
\hline Place of residence & & & & & $<.001$ & \\
\hline Urban & $\begin{array}{l}3601 \\
(45.1)\end{array}$ & $893(24.8)$ & $868(24.1)$ & $1840(51.1)$ & & \\
\hline Rural & $\begin{array}{l}4388 \\
(54.9)\end{array}$ & $\begin{array}{l}1310 \\
(29.9)\end{array}$ & $1044(23.8)$ & $2034(46.4)$ & & \\
\hline Height (cm) & $\begin{array}{l}162.94 \pm \\
9.35\end{array}$ & $\begin{array}{l}163.38 \pm \\
9.29\end{array}$ & $\begin{array}{l}163.07 \pm \\
9.29\end{array}$ & $\begin{array}{l}162.62 \pm \\
9.39\end{array}$ & 0.008 & $N>D$ \\
\hline Weight (kg) & $\begin{array}{l}73.91 \pm \\
13.54\end{array}$ & $\begin{array}{l}67.49 \pm \\
11.23\end{array}$ & $\begin{array}{l}72.96 \pm \\
12.75\end{array}$ & $\begin{array}{l}78.03 \pm \\
13.61\end{array}$ & $\begin{array}{l}< \\
0.001\end{array}$ & $\begin{array}{l}\mathrm{N}<\mathrm{P}< \\
\mathrm{D}\end{array}$ \\
\hline $\mathrm{BMI}\left(\mathrm{kg} / \mathrm{m}^{2}\right)$ & $\begin{array}{l}27.90 \pm \\
4.97\end{array}$ & $\begin{array}{l}25.34 \pm \\
4.08\end{array}$ & $27.49 \pm 4.62$ & $29.56 \pm 4.94$ & $<.001$ & $\begin{array}{l}\mathrm{N}<\mathrm{P}< \\
\mathrm{D}\end{array}$ \\
\hline Underweight & $119(1.5)$ & $64(53.8)$ & $31(26.1)$ & $24(20.2)$ & & \\
\hline
\end{tabular}




\begin{tabular}{|c|c|c|c|c|c|c|}
\hline & Total(N) & Normal (N) & $\begin{array}{l}\text { Prediabetes } \\
\text { (P) }\end{array}$ & $\begin{array}{l}\text { Diabetes } \\
\text { (D) }\end{array}$ & $P$ & \\
\hline Normal & $\begin{array}{l}2200 \\
(27.5)\end{array}$ & $\begin{array}{l}1063 \\
(48.3)\end{array}$ & $545(24.8)$ & $592(26.9)$ & & \\
\hline Overweight & $\begin{array}{l}3177 \\
(39.8)\end{array}$ & $850(26.8)$ & $825(26.0)$ & $1502(47.3)$ & & \\
\hline Obese & $\begin{array}{l}2493 \\
(31.2)\end{array}$ & $226(9.1)$ & $511(20.5)$ & $1756(70.4)$ & & \\
\hline \multicolumn{7}{|l|}{$\begin{array}{l}\text { Family history of } \\
\text { diabetes }\end{array}$} \\
\hline No & $\begin{array}{l}3703 \\
(46.4)\end{array}$ & $\begin{array}{l}1435 \\
(38.8)\end{array}$ & $904(24.4)$ & $1364(36.8)$ & & \\
\hline Yes & $\begin{array}{l}4286 \\
(53.6)\end{array}$ & 768 (17.9) & $1008(23.5)$ & $2510(58.6)$ & & \\
\hline $\begin{array}{l}\text { Hip Circumference } \\
\text { (cm) }\end{array}$ & $\begin{array}{l}102.92 \pm \\
9.65\end{array}$ & $\begin{array}{l}99.07 \pm \\
8.16\end{array}$ & $\begin{array}{l}102.14 \pm \\
9.07\end{array}$ & $\begin{array}{l}105.50 \pm \\
9.91\end{array}$ & $\begin{array}{l}< \\
0.001\end{array}$ & $\begin{array}{l}\mathrm{N}<\mathrm{P}< \\
\mathrm{D}\end{array}$ \\
\hline $\begin{array}{l}\text { Waist Circumference } \\
(\mathrm{cm})\end{array}$ & $\begin{array}{l}97.98 \pm \\
12.32\end{array}$ & $\begin{array}{l}91.64 \pm \\
11.04\end{array}$ & $\begin{array}{l}96.79 \pm \\
11.23\end{array}$ & $\begin{array}{l}102.18 \pm \\
11.84\end{array}$ & $<001$ & $\begin{array}{l}\mathrm{N}<\mathrm{P}< \\
\mathrm{D}\end{array}$ \\
\hline Waist/Hip Ratio & $0.95 \pm 0.06$ & $0.92 \pm 0.07$ & $0.95 \pm 0.06$ & $0.97 \pm 0.05$ & $<.001$ & $\begin{array}{l}\mathrm{N}<\mathrm{P}< \\
\mathrm{D}\end{array}$ \\
\hline Waist/Height Ratio & $0.60 \pm 0.09$ & $0.56 \pm 0.08$ & $0.60 \pm 0.08$ & $0.63 \pm 0.09$ & $<.001$ & $\begin{array}{l}\mathrm{N}<\mathrm{P}< \\
\mathrm{D}\end{array}$ \\
\hline
\end{tabular}

\section{Distribution of ADA risk score}

Figure 2 presents the frequency of ADA risk scores among participants. The mean ADA risk score for all respondents were $4.48(S D=1.55)$, and using a recommended cut-off values, the prevalence of high risk subjects for preDM and DM were, $23.9 \%(n=1912)$ and $48.5 \%(n=3874)$, respectively.

\section{Comparison of groups}

As presented in Table 1, all of the anthropometric indices (i.e., BMI, HC, WC, WHpR, and WHtR) in diabetes group were higher than those in prediabetes and normal groups. In addition, all anthropometric indices in prediabetes group were also higher than in normal group.

\section{ROC curve analysis}


The results of ROC curve analyses to examine the diagnostic accuracy of the anthropometric indices for detecting patients with diabetes based on ADA risk score are presented in Table 2. Based on the AUC values, the anthropometric indices that had the highest diagnostic value was "Waist Circumference" followed by "BMI" in differentiating patients with diabetes and healthy subjects. Figure 3

Table 2

Diagnostic accuracy of anthropometric indices for detecting participants with diabetes using ROC curve analysis

\begin{tabular}{|lllll|}
\hline & Cut-Point & Sensitivity (\%) & Specificity (\%) & AUC \\
\hline Weight & 73 & 62.1 & 63.0 & 0.670 \\
\hline BMI & 29.16 & 52.8 & 77.2 & 0.693 \\
\hline Hip Circumference & 103 & 55.1 & 67.6 & 0.653 \\
\hline Waist Circumference & 97.1 & 66.1 & 63.4 & 0.695 \\
\hline Waist to Hip Ratio & 0.94 & 73.8 & 50.0 & 0.663 \\
\hline Waist to Height Ratio & 0.59 & 66.1 & 56.8 & 0.666 \\
\hline AUC: Area under the Curve & & & \\
\hline
\end{tabular}

\section{Discussion}

Finding from PGCS showed that, near to half of non diabetic participants (48\%) were high risk for developing DM and also more than 23\% were high risk for preDM. In a large survey (National Health and Nutrition Examination Survey) conducted from 1999 to 2006, ADA risk score found 35\% of subjects were high risk for DM [20]. In a recent descriptive large study conducted in central of Iran, prevalence of DM and preDM was $16.1 \%$ and $24.5 \%$, respectively [21]. Evidence shows an increase of $35 \%$ in DM prevalence in 2011 compared to 2005. In parallel with our prediction, a Meta analysis modeling study estimated 9.2 million Iranian people will have diabetes by the year 2030(3). This significant increase in DM prevalence and also in DM complications, implementation of prevention and control programs seems to be substantial. Finding from Iranian National Surveys (2007-2016) on 7665 and 93,733 adults with and without known diabetes showed secondary prevention in individual level was effective to control of FBS level but primary prevention in non diabetic people had no positive effect [22].

According to our study, frequency of high risk subjects for DM were superior in male when compared to female as well as in urban area rather than rural area. Although, more subjects of GCS population lived in rural area. In primary analysis of GCS, diabetes was more prevalent in females (27.3\%) rather than males $(20.2 \%)(17)$. The finding of PERSIAN Kharameh cohort study showed that subjects living in urban areas were more likely to display metabolic syndrome and DM than those living in rural areas [23]. Contrary to our study in Kharameh cohort study, prevalence of impaired fasting glucose in females was higher than 
males. On the other hands, according to International Diabetes Federation, there were about 14 million more men than women with diabetes (198 million men vs 184 million women) in 2013 and it seems the difference increases to 15 million (303 million men vs 288 million women) by 2035[24].Furthermore, in a cross sectional study among adults aged 20-80 years in northern part of Iran was observed DM were most prevalent in males than females [25].

In present study, subjects with high risk for DM had higher waist and hip circumference, waist/hip ratio and waist/height ratio compared to those with low risk group and also to preDM group. Correlation of obesity and risk of developing DM was reported in previous evidence [25-28]. According to our finding, WC followed by BMI had highest diagnostic value in identifying high risk men and women for developing DM. Although, a prospective study on Iranian adult men in 2006 indicated WHtR is better than BMI and WC in detecting urban men population who was at risk of diabetes [29]. On the other hands, according to a study based on Isfahan Cohort Study (ICS), WC compared to other anthropometric indices was better indicator of metabolic syndrome in Iranian women and men population [30]. Furthermore, previous researches showed WC is strongly related to all-cause and cardiovascular mortality with or without adjustment for BMI [31, 32]. Recent review indicated waist circumference is associated with health outcomes within all BMl categories in every sex and age [33].

In the present study, cut-points of WC and BMI for identifying high risk people for developing DM were 97 and 29, respectively which were higher than the recommended cutoff for major CVD risk factors in previous studies [30,34,35]. First Iranian study on anthropometric indices proposed WC and BMI cut-offs for detecting DM, between 82-95 cm and 25-29 in women and men, in various age groups [34]. Iranian National Committee of Obesity reported people with WC of $\geq 90 \mathrm{~cm}$ are at high risk for CVD event [35].

Cut-points of WHpR to identify high risk individual for developing DM in the present study were 0.94 that somewhat close to the recommended cut point in other studies. For example, P Mirmiran et al found cutpoints of WHR between 0.86 and 0.97 for men and between 0.78 and 0.92 for women were high risk for various CVD risk factors [34]. In our study, the diagnostic values of WHpR and WHtR in identifying high risk people for DM were relatively similar. The diagnostic value of WHtR in Chinese cohort study was reported 0.679 that was in parallel with our finding(AUC: 0.666)[36].A recent study in middle east region showed WHtR can better predict the risk of DM and also HTN[37]. Finding from a population based study of 1852 Iranian males aged $\geq 20$ years showed WHtR was a strong predictor for developing type 2 diabetes in the future [29].

In total, finding high risk people in individual and community level may help people and policy makers to develop and plan prevention strategies. We detect a considerable numbers of Iranian adult lived in northern part of Iran were high risk for developing DM and PreDM. Hence, note to lifestyle modification in individual and community level seems to be substantial. Our study was based on PG Cohort Study with large sample size and accurate data collection. Data collection and measurement were based on Persian cohort study standards that increase the precision of the finding. However, this study involves some limitation. First, due to cross sectional nature of present study design, we couldn't define the actual risk of 
study subjects and compare to their calculated risk. However, the validity and sensitivity of ADA risk score among GCS population could be assess in the future years using long term follow up duration.

Furthermore, some study variables like physical activity, history of gestational diabetes were measured based on self-reported that increases the probability of recall bias.

\section{Conclusion}

In conclusion, present study showed that a large number of people in northern part of Iran were in high risk category of ADA risk score for developing DM and PreDM. High risk group were more prevalent in male rather than female and also urban residents. According to our finding, among abdominal obesity variables, waist circumference appears to be stronger than others in identifying high risk people for developing DM in the future.

\section{List Of Abbreviations}

DM: Diabetes Mellitus; ADA: American Diabetes Association; PGCS: PERSIAN Guilan Cohort Study; ROC: Receiver operating characteristic; AUC: Area Under the Curve; WC: Waist Circumference; WHO: World Health Organization; TLGS: Tehran Lipid and Glucose Study; GCS: Guilan cohort study; WHpR: Waist to Hip Ratio; WHtR: Waist to Height Ratio; HTN: History of Hypertension; HC: Hip Circumference; METs: Metabolic Equivalent Rates; BMI:Body Mass Index

\section{Declarations}

\section{Ethics approval and consent to participate}

The informed consent and study design were reviewed and approved by vice-chancellor for research of Guilan University of medical science according to Helsinki declaration (research number: (IR.GUMS.REC.1398.241).

\section{Consent for publication}

Not applicable

\section{Availability of data and materials}

Datasets used during the study are available from the corresponding author on reasonable request.

\section{Competing interests}

The authors declare that they have no competing interests 


\section{Funding}

This work was supported by vice-chancellor for research of Guilan University of medical science.

\section{Authors' contributions}

TH and FJ and FM-G were involved in the study design. SM and MN data analysis. SS data collection and contributed to data interpretation.SS and TH literature searched. TH, FJ, FM-G and MN wrote the initial draft of the manuscript, TH and FJ and FM-G contributed toward its final version. FJ generated of figures. All authors were involved in writing the paper and had final approval of the submitted and published versions

\section{Acknowledgments}

The authors gratefully acknowledge the all participants in the GCS and all staffs of the Gastrointestinal and Liver Disease Research Center and vice-chancellor for research of Guilan University of medical science.

\section{Authors' information (optional)}

Not applicable.

\section{References}

1. I.D . Federation. IDF diabetes atlas ninth edition .2019, (2019).

2. Haghdoost AA, Rezazadeh Kermani M, Sadghirad B, Baradaran HR. Prevalence of type 2 diabetes in the Islamic Republic of Iran: systematic review and meta-analysis. East Mediterr Health J. 2009; 15 (3): 591-599.

3. Javanbakht M, Mashayekhi A, Baradaran H.R, Haghdoost A,Afshin A. Projection of diabetes population size and associated economic burden through 2030 in Iran: evidence from microsimulation Markov model and Bayesian meta-analysis. PloS one.2015; 10 (17): e0132505. https://doi.org/10.1371/journal.pone.0132505.

4. Esteghamati A,Larijani B,Aghajani M.H, Ghaemi F,Kermanchi J, Shahrami A,Saadat M, Esfahani E.N, Ganji M, Noshad S, Khajeh E, Ghajar A, Heidari B, Afarideh M, Mechanick JI, Ismail-Beigi F. Diabetes in Iran: prospective analysis from first nationwide diabetes report of National Program for Prevention and Control of Diabetes (NPPCD-2016). Sci Rep .2017; 7 :13481. https://doi: 10.1038/s41598-01713379-z.

5. Said M.A,Verweij N, Van der Harst P. Associations of Combined Genetic and Lifestyle Risks With Incident Cardiovascular Disease and Diabetes in the UK Biobank Study. JAMA Cardiology .2018;3(8) 
:693-702. https:// doi:10.1001/jamacardio.2018.1717.

6. Gong Q, Zhang P,Wang J, Ma J, An Y,Chen Y, Zhang B, Feng X,Li H, Chen X,ChengY.J, Gregg E.W, Hu Y, Bennett P.H, Li G.Morbidity and mortality after lifestyle intervention for people with impaired glucose tolerance: 30-year results of the Da Qing Diabetes Prevention Outcome Study. Lancet Diabetes Endocrinol. 2019; 7 (6): 452-461. https:// doi: 10.1016/S2213-8587(19)30093-2. Epub 2019 Apr 26.

7. Galaviz K.I, Weber M.B, Straus A,Haw J.S, Narayan K.V,Ali M.K. Global diabetes prevention interventions: a systematic review and network meta-analysis of the real-world impact on incidence, weight, and glucose. Diabetes Care .2018; 41 (7): 1526-1534. https:// doi: 10.2337/dc17-2222.

8. W.H. Organization, Global action plan for the prevention and control of noncommunicable diseases 2013:2013-2020.

9. Alberti K.G.M.M, Zimmet P, Shaw J. International Diabetes Federation: a consensus on Type 2 diabetes prevention, Diabetic Medicine .2007; 24 (5): 451-463, https:// doi: 10.1111/j.14645491.2007.02157.x.

10. Abbasi A, Peelen L.M, Corpeleijn E, Van der Schouw Y.T,Stolk R.P,Spijkerman A.M, Van der A.DL,Moons K.G,Navis G,Bakker S.J, Beulens JW. Prediction models for risk of developing type 2 diabetes: systematic literature search and independent external validation study. BMJ .2012; 345: 5900.http://www.bmj.com/content/345/bmj.e5900.

11. Lindström J,Tuomilehto J. The diabetes risk score: a practical tool to predict type 2 diabetes risk. Diabetes care .2003; 26 (3) :725-731, https:// doi: 10.2337/diacare.26.3.725.

12. Chen L,Magliano D.J,Balkau B,Colagiuri S,Zimmet P.Z,Tonkin A.M,Mitchell P, Phillips P.J, Shaw J.E. AUSDRISK: an Australian Type 2 Diabetes Risk Assessment Tool based on demographic, lifestyle and simple anthropometric measures. Med J Aust. 2010; 192 (4): 197-202.

13. American Diabetes Association. Diabetes Risk Test.Available from: http://www.diabetes.org/risk-test (accessed February 2007).

14. Bang H,Edwards A.M,Bomback A.S,Ballantyne C.M,Brillon D,Callahan M.A,Teutsch S.M,Mushlin A.I, L.M. Kern L.M. A patient self-assessment diabetes screening score:: development, validation, and comparison to other diabetes risk assessment scores. Annals of internal medicine $.2009 ; 151$ (11) :775-83.https://doi.org/10.7326/0003-4819-151-11-200912010-00005.

15. Aekplakorn W,Bunnag P,Woodward M,Sritara P,Cheepudomwit S,Yamwong S,Yipintsoi T, Rajatanavin R. A risk score for predicting incident diabetes in the Thai population. Diabetes care. 2006; 29 (8): 1872-1877, https:// doi: 10.2337/dc05-2141.

16. Lotfaliany M, Hadaegh F, Asgari S,Mansournia M.A,Azizi F,Oldenburg B,Khalili D. Non-invasive risk prediction models in identifying undiagnosed type 2 diabetes or predicting future incident cases in the Iranian population. Arch Iran Med. 2019; 22 (3) :116-124.

17. Mansour-Ghanaei F, Joukar F,Naghipour M.R,Sepanlou S.G,Poustchi H,Mojtahedi K,Balou H.A, Heidarzadeh A, Malekzadeh R. The PERSIAN Guilan Cohort Study (PGCS).Arch Iran Med. 2019; 22 (1): 39-45. 
18. Poustchi H,Eghtesad S,Kamangar F,Etemadi A,Keshtkar A.A,Hekmatdoost A,Mohammadi Z, Mahmoudi Z,Shayanrad A,Roozafzai F,et al. Prospective epidemiological research studies in Iran (the PERSIAN Cohort Study): rationale, objectives, and design. Am J Epidemiol .2018; 187 (4):647655.https:// doi: 10.1093/aje/kwx314.

19. Eghtesad S,Mohammadi Z,Shayanrad A,Faramarzi E,Joukar F,Hamzeh B,Farjam M,Sakhvidi M.J.Z, Miri-Monjar M,Moosazadeh M,et al. The PERSIAN cohort: providing the evidence needed for healthcare reform. Arch Iran Med .2017, 20 (11) 691-695.

20. Bang H, Edwards A.M, Bomback A.S,Ballantyne C.M,Brillon D,Callahan M.A,Teutsch S.M, Mushlin A.I,Kern L.M. Development and validation of a patient self-assessment score for diabetes risk, Ann Intern Med. 2009; 151 (11) :775-783, https://doi.org/10.7326/0003-4819-151-11-200912010-00005.

21. Mirzaei M,Rahmaninan M,Mirzaei M,Nadjarzadeh A,Dehghani tafti A.A. Epidemiology of diabetes mellitus, pre-diabetes, undiagnosed and uncontrolled diabetes in Central Iran: results from Yazd health study. BMC Public Health .2020; 20:166, https://doi.org/10.1186/s12889-020-8267-y.

22. Hamid M,Mojtaba L,Afshin O,Farzad H, Fereidoun A,Moein Y,Farshad F,Davood K. Trends in cardiovascular risk factors in diabetic patients in comparison to general population in Iran: findings from National Surveys 2007-2016, Scientific Reports (Nature Publisher Group) .2020;10 (1):11724. https:// doi:10.1038/s41598-020-68640-9.

23. Nikbakht H.A,Rezaianzadeh A,Seif M,Ghaem H. Prevalence of metabolic syndrome and its components among a population-based study in south of Iran, PERSIAN Kharameh cohort study. Clinical Epidemiology and Global Health .2020;8 (3):678-683. https://doi.org/10.1016/j.cegh.2020.01.001.

24. International Diabetes Federation. Brussels, Belgium: International Diabetes Federation; 2013. IDF Diabetes Atlas. 6th ed.Available from: https://www.idf.org/e-library/epidemiology-research/diabetesatlas/19-atlas-6th-edition.html.

25. Hajian-Tilaki K,Heidari B. Is waist circumference a better predictor of diabetes than body mass index or waist-to-height ratio in Iranian adults?. Int J Prev Med .2015; 6 (1): 5-5. https:// doi: 10.4103/20087802.151434.eCollection 2015.

26. Hadaegh F,Bozorgmanesh M.R,Ghasemi A,Harati H,Saadat N,Azizi F. High prevalence of undiagnosed diabetes and abnormal glucose tolerance in the Iranian urban population: Tehran Lipid and Glucose Study. BMC Public Health .2008; 8:176, https:// doi:10.1186/1471-2458-8-176.

27. Esteghamati A,Etemad K,Koohpayehzadeh J,Abbasi M,Meysamie A,Noshad S,Asgari F, Mousavizadeh M, Rafei A,Khajeh E,Neishaboury M,Sheikhbahaei S,Nakhjavani M. Trends in the prevalence of diabetes and impaired fasting glucose in association with obesity in Iran: 2005-2011, Diabetes Research and Clinical Practice. 2014; 103 (2): 319-327, https:// doi:

10.1016/j.diabres.2013.12.034.

28. Shabnam A.A,Homa K, Reza M.T.M,Bagher L,Hossein F.M,Hamidreza A. Cut-off points of waist circumference and body mass index for detecting diabetes, hypercholesterolemia and hypertension 
according to National Non-Communicable Disease Risk Factors Surveillance in Iran.Arch Med Sci. 2012; 8 (4): 614-621, https:// doi: 10.5114/aoms.2012.30284.

29. Hadaegh F,Zabetian A,Harati H,Azizi F. Waist/height ratio as a better predictor of type 2 diabetes compared to body mass index in Tehranian adult men-a 3.6-year prospective study. Experimental and Clinical Endocrinology \& Diabetes .2006; 114 (6): 310-315. https:// doi: 10.1055/s-2006-924123.

30. Gharipour M, Sarrafzadegan N, Sadeghi M,Andalib E,Talaie M,Shafie D,Aghababaie E. Predictors of metabolic syndrome in the Iranian population: waist circumference, body mass index, or waist to hip ratio?. Cholesterol. 2013; 2013: 198384. https:// doi: 10.1155/2013/198384

31. Cerhan J.R, Moore S.C, Jacobs E.J,Kitahara C.M,Rosenberg P.S,Adami H.O,Ebbert J.O,English D.R, Gapstur S.M, Giles G.G,et al. A pooled analysis of waist circumference and mortality in 650,000 adults, in: Mayo Clin Proc. Mayo Clinic Proceedings .2014; 8(3): 335-345. https://doi: 10.1016/j.mayocp.2013.11.011.

32. Song X,Jousilahti P, Stehouwer C, Söderberg S, Onat A,Laatikainen T,Yudkin J,Dankner R,Morris R, Tuomilehto J, Qiao Q. Comparison of various surrogate obesity indicators as predictors of cardiovascular mortality in four European populations. European Journal of Clinical Nutrition .2013; 67:1298-1302.

33. Ross R,Neeland I.J,Yamashita S,Shai I,Seidell J,Magni P,Santos R.D,Arsenault B, Cuevas A,Hu F.B, Griffin B.A,Zambon A,Barter P,Fruchart J.C,Eckel R.H,Matsuzawa Y,Després J.P. Waist circumference as a vital sign in clinical practice: a Consensus Statement from the IAS and ICCR Working Group on Visceral Obesity. Nature Reviews Endocrinology .2020; 16 (3): 177-189. https://doi: 10.1038/s41574019-0310-7.

34. Mirmiran P, Esmaillzadeh A, Azizi F. Detection of cardiovascular risk factors by anthropometric measures in Tehranian adults: receiver operating characteristic (ROC) curve analysis. Eur J Clin Nutr .2004; 58 (8): :1110-1118.

35. Fereidoun Azizi M,Davood Khalili M,Hassan Aghajani M, Alireza Esteghamati M,Farhad Hosseinpanah M, Alireza Delavari M, Hadaegh F. Appropriate waist circumference cut-off points among Iranian adults: the first report of the Iranian National Committee of Obesity. Arch Iran Med .2010; 13 (3): 243-244.

36. Ding J,Chen X,Bao K,Yang J,Liu N,Huang W, Huang P,Huang J,Jiang N,Cao J, Cheng N,Wang M,Hu $X$, Zheng S,Bai Y. Assessing different anthropometric indices and their optimal cutoffs for prediction of type 2 diabetes and impaired fasting glucose in Asians: The Jinchang Cohort Study. J Diabetes. 2020;12 (5):372-384. https://doi.org/10.1111/1753-0407.13000.

37. Khader Y, Batieha A,Jaddou H,El-Khateeb M,Ajlouni K. The performance of anthropometric measures to predict diabetes mellitus and hypertension among adults in Jordan. BMC Public Health .2019; 19: 1416, https://doi.org/10.1186/s12889-019-7801-2.

\section{Figures}




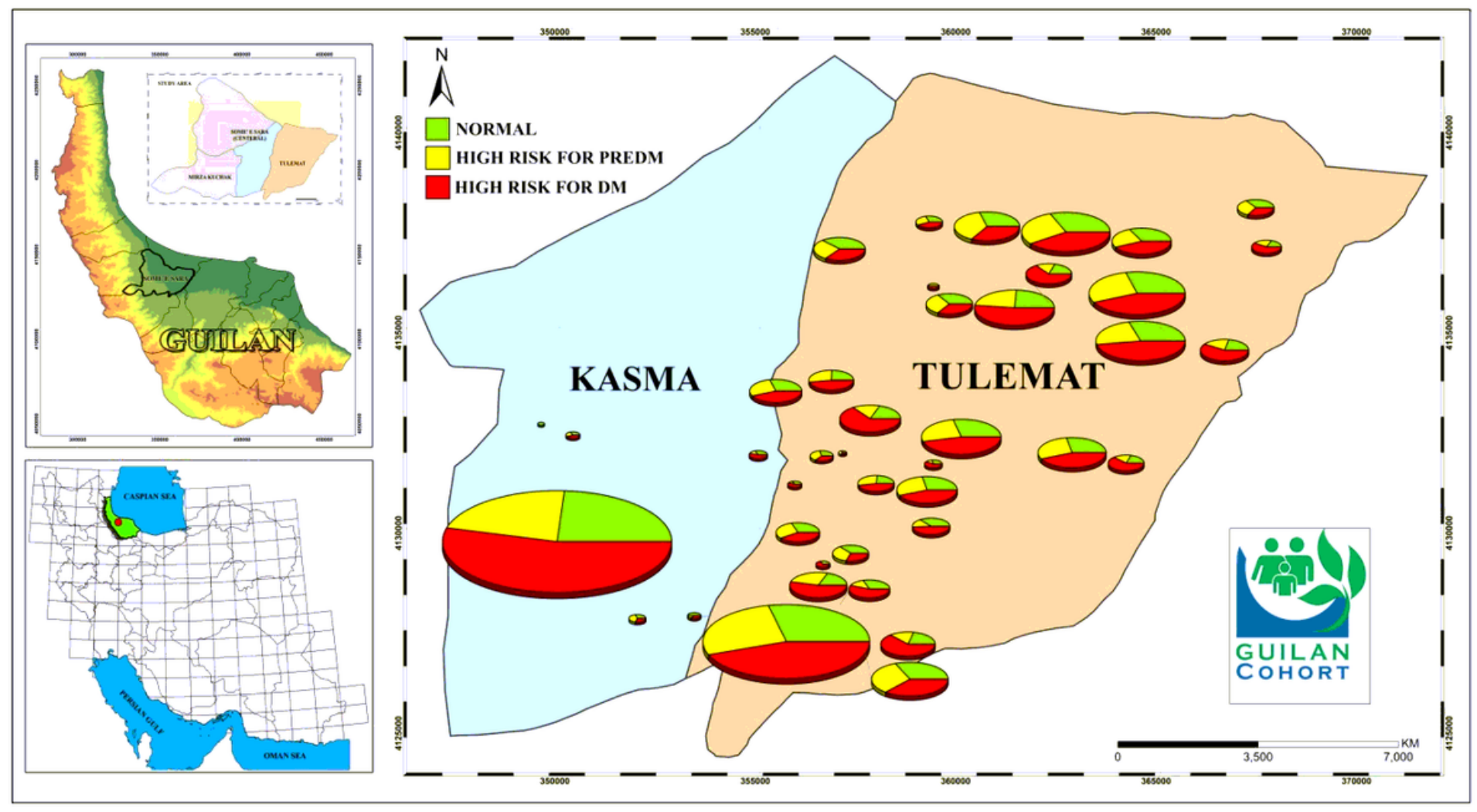

\section{Figure 1}

The geographic distributions of study participants according to ADA score category (normal, high risk for preDM, high risk for DM)

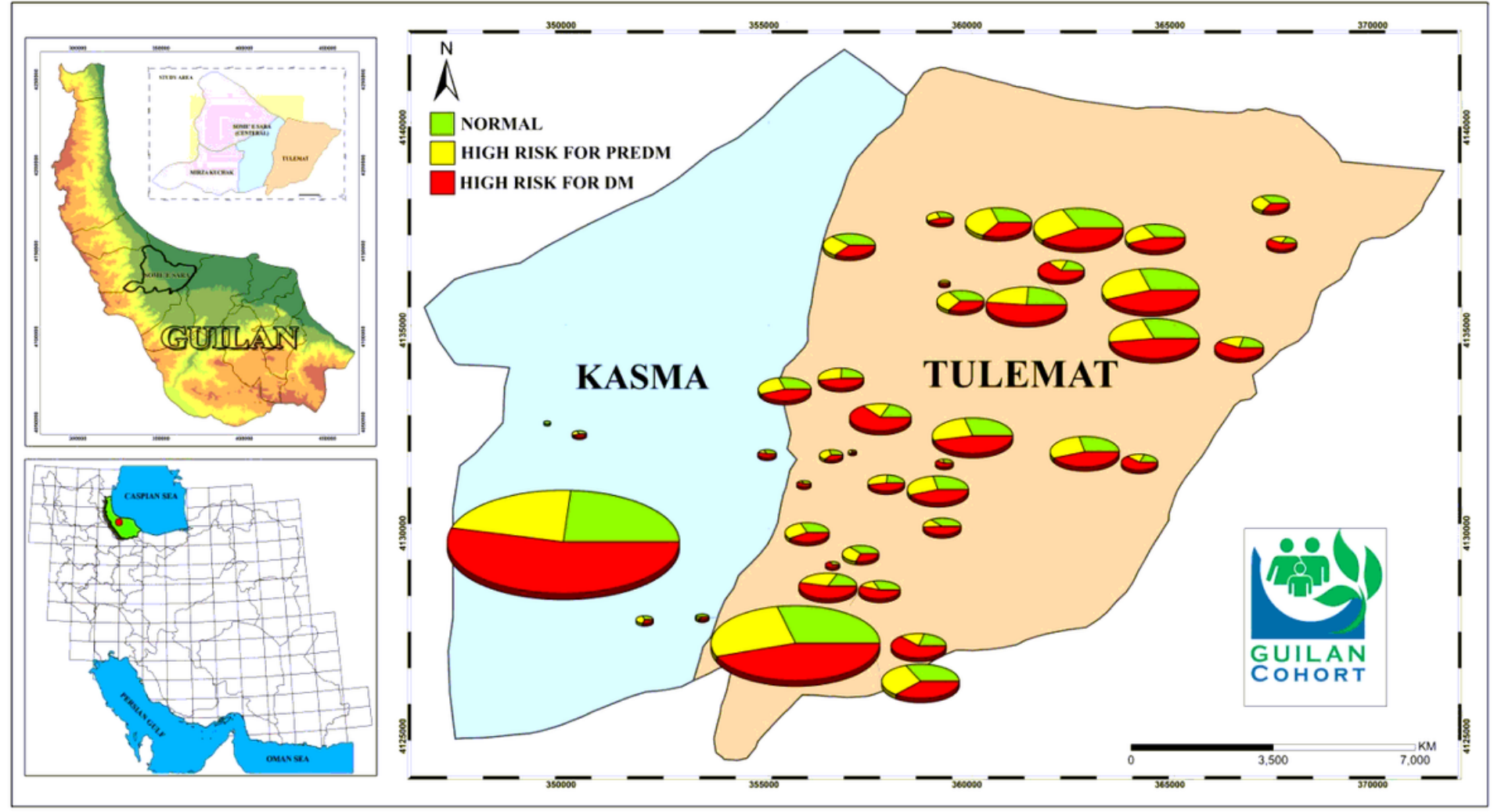


Figure 1

The geographic distributions of study participants according to ADA score category (normal, high risk for preDM, high risk for DM)

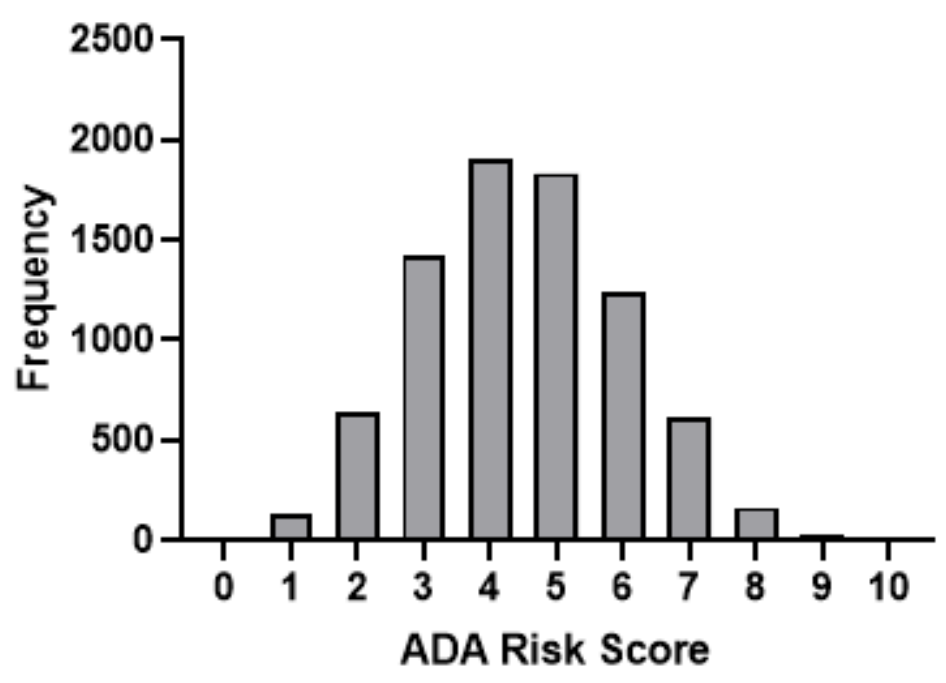

Figure 2

Distribution of ADA risk score among adults participants without diagnosed DM in the Persian Guilan Cohort Study $(\mathrm{n}=7989)$

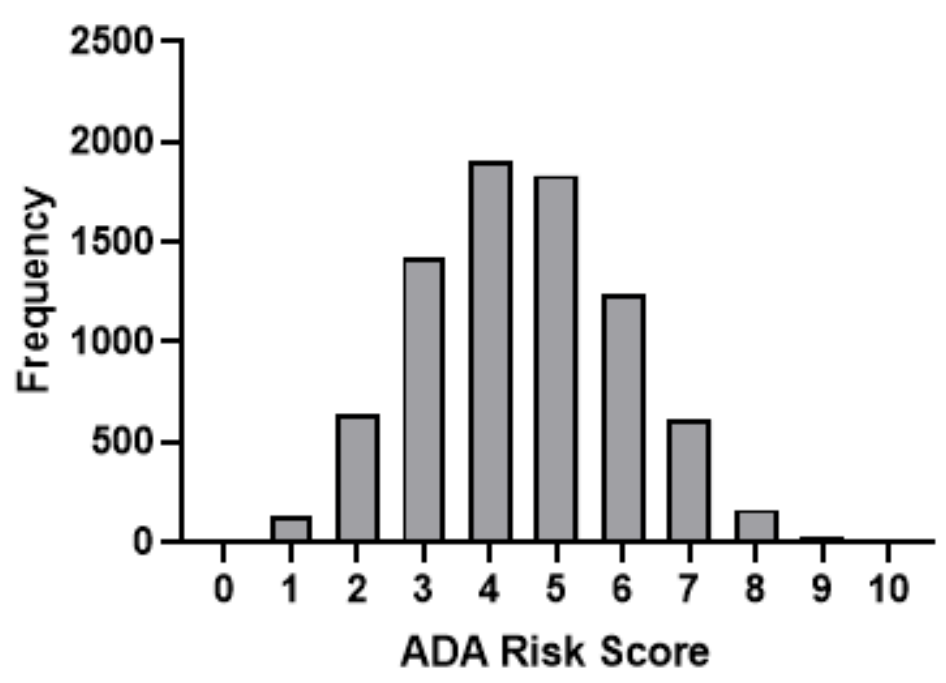

Figure 2

Distribution of ADA risk score among adults participants without diagnosed DM in the Persian Guilan Cohort Study $(n=7989)$ 


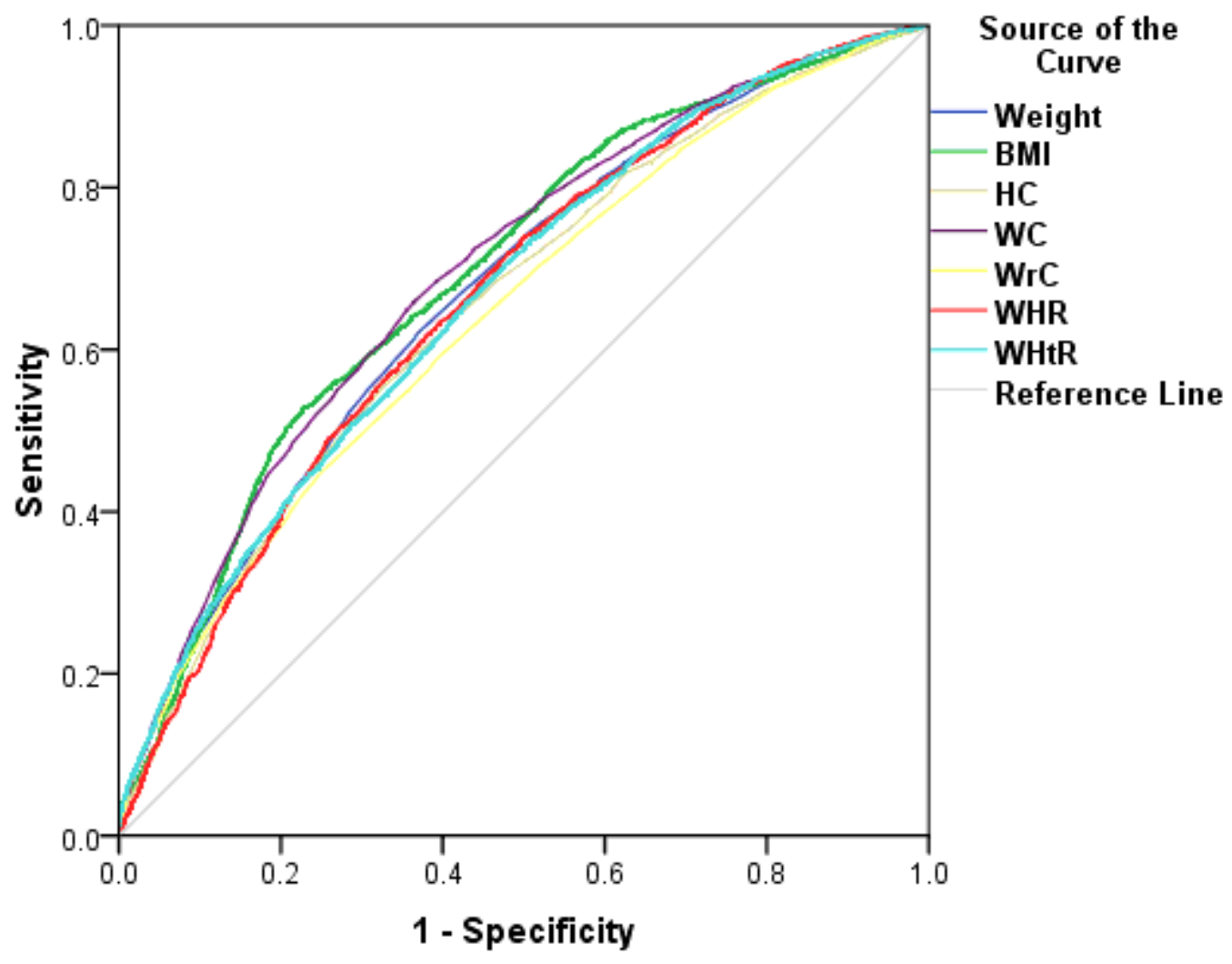

Figure 3

Diagnostic accuracy of anthropometric indices for detecting participants with diabetes using ROC analysis 


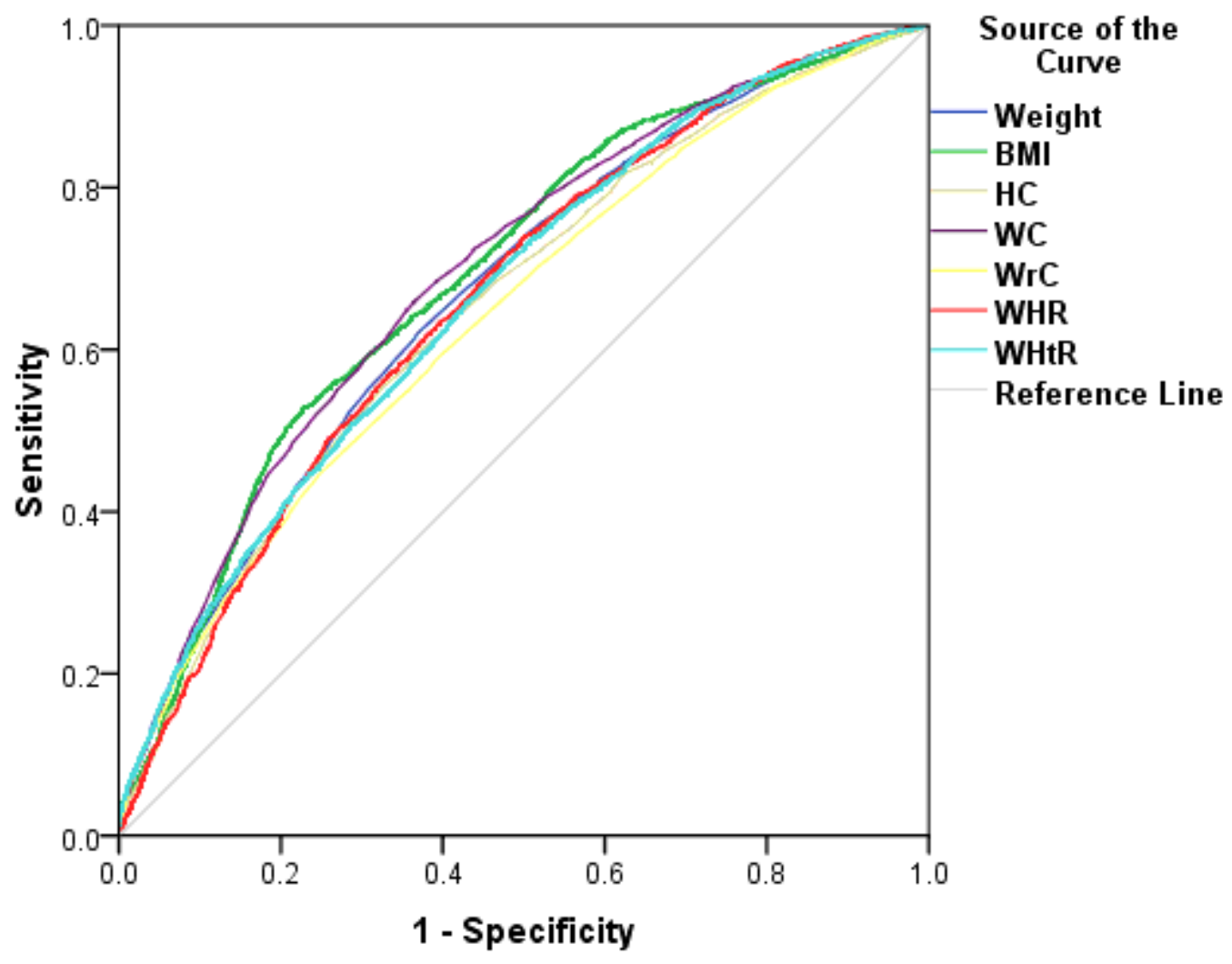

Figure 3

Diagnostic accuracy of anthropometric indices for detecting participants with diabetes using ROC analysis 